\title{
Las movilidades interna y de retorno de los varones migrantes mexicanos a Estados Unidos en perspectiva longitudinal (1942-2011)*
}

\author{
Eduardo Torre Cantalapiedra** \\ Silvia E. Giorguli****
}

Los patrones de movilidad de los mexicanos en Estados Unidos durante todo el siglo XX hasta la fecha han variado en el tiempo y han dependido de las características personales de los migrantes. Mediante la utilización de los datos longitudinales del Mexican Migration Project, en este artículo se describen los cambios residenciales (migración interna o retorno) vinculados al trabajo de los hombres mexicanos después de su primera llegada a Estados Unidos, y cómo éstos varían según la etapa de la migración (bracero, pre-IRCA y post-IRCA). Se analiza cómo las probabilidades de cada tipo de movimiento difieren según el tiempo de llegada, el estatus de documentación y la ocupación.

Palabras clave: migración internacional, política migratoria, migración de retorno, indocumentación.

Fecha de recepción: 25 de julio de 2014.

Fecha de aceptación: 28 de noviembre de 2014.

Internal and Return Mobilities of Mexican Male Migrants in U.S. from a Longitudinal Perspective (1942-2011)

The patterns of mobility among Mexicans living in the U.S. have shifted since the XX century until today. Mobility depends on the personal characteristics of the Mexican migrants. Using the longitudinal data provided by the Mexican Migration Project, we

* Este trabajo se deriva de las ponencias presentadas en la Reunión Anual de la Population Association of America, Boston, 2014; la XII Reunión Nacional de Demografía organizada por la Sociedad Mexicana de Demografía, Ciudad de México, 2014; y el VI Congreso de la Asociación Latinoamericana de Población, Lima, 2014. Agradecemos los comentarios de Julieta Pérez Amador, Beatriz Novak, Marcela Cerrutti y Sebastián Felipe Bruno a versiones anteriores de este trabajo. Agradecemos también los comentarios de los dictaminadores anónimos.

** Estudiante del doctorado en Estudios de Población, Centro de Estudios Demográficos, Urbanos y Ambientales de El Colegio de México. Dirección postal: Camino al Ajusco núm. 20, col. Pedregal de Santa Teresa, Tlalpan, 10740, México, D.F., México. Correo electrónico: <etorre@ colmex.mx>.

*** Profesora investigadora del Centro de Estudios Demográficos, Urbanos y Ambientales de El Colegio de México. Dirección postal: Camino al Ajusco núm. 20, col. Pedregal de Santa Teresa, Tlalpan, 10740, México, D.F., México. Correo electrónico: $<$ sgiorguli@colmex.mx $>$.

ESTUDIOS DEMOGRÁFICOS Y URBANOS, VOL. 30, NÚM. 1 (88), 2015, 7-43 
describe the changes of residence (internal and return migration) linked to labor transitions of Mexican men after their first arrival to United States. We analyze changes in the patterns in three migration stages (bracero, pre-IRCA and post-IRCA). We estimate the probabilities of the different types of migration by duration of residence, documentation status and occupation.

Key words: international migration, migration policy, return migration, undocumented migration.

\section{Introducción}

La intensa migración entre México y Estados Unidos conlleva diversas modalidades de movilidad que siguen al primer viaje. Después de una primera migración a Estados Unidos se abren otras opciones de movimientos dentro de dicho país (migraciones internas), de regreso a México o inclusive la migración a otros países de destino (véase más adelante el esquema 1). Hasta ahora el tema de las movilidades que experimentan los migrantes mexicanos se ha estudiado de manera separada. Por un lado, junto con la literatura sobre la integración de los diversos grupos de migrantes, se analizan los patrones de dispersión geográfica de los mexicanos en los diversos estados de la Unión Americana y su vinculación con el perfil de éstos (capital humano y estatus de documentación, principalmente) (Nogle, 1997; Gurak y Kritz, 2000; Kritz, Gurak y Lee, 2013; Zúñiga y Hernández León, 2005). Por otro, de manera paralela se ha desarrollado una amplia literatura sobre el retorno de Estados Unidos hacia México y sus cambios en el tiempo (Massey y Espinosa, 1997; Lindstrom, 1996; Massey, Durand y Riosmena, 2006; Masferrer y Roberts, 2012). Sin embargo existen pocos estudios que analicen los dos procesos de manera simultánea, ya sea por la falta de datos longitudinales (en el caso de la movilidad de mexicanos en Estados Unidos) o por la escasez de información que permita vincular la movilidad en ambos lados de la frontera.

El objetivo principal de este trabajo es analizar de manera simultánea los patrones de movilidad de los mexicanos desde que llegan por primera vez a Estados Unidos mediante una perspectiva longitudinal; en concreto, analizamos los patrones de movilidad de los hombres mexicanos que llegaron a trabajar al territorio estadounidense después de los 14 años. ${ }^{1}$ El estudio abarca las primeras migraciones en 1942

${ }^{1}$ El trabajo se centra sólo en los migrantes hombres por varias razones. En primer lugar, en el periodo anterior a IRCA (Immigration Reform and Control Act) la migración 
hasta la primera década de este siglo. ${ }^{2}$ Nos interesa conocer en qué medida los varones migrantes han permanecido en el estado de residencia a su arribo a dicho país, cambiaron su lugar de residencia y de empleo a otro estado, o regresaron a México. ${ }^{3}$

Con base en los hallazgos previos sobre movilidad interna de los migrantes y sobre la migración de retorno, suponemos que ambos procesos dependerán del tiempo de estancia en Estados Unidos (duración), bajo el supuesto que conforme éste aumente, las probabilidades de regresar al país de origen serán menores. Asimismo, el análisis longitudinal de los datos nos permite apreciar las diferencias a lo largo de la historia de la migración entre ambos países. Así como los perfiles y la dinámica de migración desde México hacia Estados Unidos han cambiado en el transcurso del tiempo dependiendo de las políticas migratorias, el contexto económico en ambos países y la propia dinámica de la migración, suponemos que los patrones de movilidad después de la primera migración también serán diferentes según la etapa migratoria y sus correspondientes perfiles específicos. En esa misma lógica y dado que nos concentramos en migraciones laborales, analizamos si las condiciones económicas en ambos países -medidas con la tasa de desempleo en Estados Unidos y con los cambios en el PIB per cápita en México- modifican la preferencia por el retorno o favorecen la permanencia en el país del norte así como la movilidad interna.

femenina era menor, lo cual dificulta la comparación en el tiempo por los pocos casos disponibles. En segundo, la fuente de datos, el MMP (Mexican Migration Project), tiene historias de vida completas para los jefes del hogar -en su mayoría varones- desde que comenzó el levantamiento en 1987. La información sobre la historia migratoria completa de los cónyuges -en su mayoría mujeres- sólo está disponible para las comunidades encuestadas a partir de 1998. Finalmente, la base de datos no contiene el dato específico sobre el estado de residencia año con año; se tiene el dato sobre el estado en el que se trabajó (JOBSTATE), el cual se utilizó como proxy del lugar de residencia. Dadas las fluctuaciones en la condición de actividad de las mujeres y las bajas tasas de participación económica, la utilización de esta variable sería imprecisa para el caso de las mujeres que migraron por primera vez a Estados Unidos.

${ }_{2}$ El carácter retrospectivo del MMP nos permite reconstruir la historia migratoria de los jefes de hogar que estaban en la comunidad en el momento de la entrevista. Esto implica que para las migraciones de más tiempo existe un posible sesgo, dado que la muestra se refiere sólo a la movilidad de los migrantes sobrevivientes. Aun a pesar de lo anterior, el MMP sigue siendo la fuente principal de datos para poder analizar cambios en el tiempo vinculados con otros procesos familiares, locales y nacionales.

${ }^{3}$ Nos concentramos en movilidades vinculadas a cambios en el empleo. Dado el diseño de la investigación en la que se basa nuestro análisis, no podemos incluir otras razones que impulsan la migración interna tales como las políticas, las familiares y las culturales. 
Finalmente, entre los diversos determinantes de la migración interna y de retorno, consideramos que la situación de documentación y el tipo de ocupación definirán en gran medida el patrón de movilidad de los mexicanos que llegan a Estados Unidos. La situación de documentación favorecería la migración interna e inhibiría el retorno a México. Por la naturaleza misma del trabajo agrícola, suponemos que habrá una mayor movilidad de aquellos ocupados en este sector de actividad económica.

\section{Antecedentes de los patrones de movilidad de los mexicanos en Estados Unidos}

Los demógrafos y otros académicos han descrito, analizado y explicado los patrones de movilidad residencial de los mexicanos en Estados Unidos en cuanto al retorno y a los desplazamientos entre los estados de la Unión. En el presente trabajo pretendemos analizar ambas movilidades tal y como se expone en el esquema 1. Además asumimos que, en consonancia con los cambios en la dinámica migratoria entre ambos países, las movilidades de retorno y la interna vinculadas a cambios en la situación laboral pueden variar a lo largo de las diferentes etapas de la migración.

La gran mayoría de los trabajos sobre movilidad interestatal de los extranjeros en Estados Unidos se centra en el debate sobre si los inmigrantes de diferentes orígenes nacionales se están concentrando o dispersando a lo largo del territorio estadounidense (Newbold, 1999; Frey y Liaw, 1999; Kritz, Gurak y Lee, 2013; Ellis y Goodwin-White, 2006; Zúñiga y Hernández León, 2005). Algunos de los aspectos tratados por estos autores son: la formación y el mantenimiento de los enclaves étnicos; la movilidad diferenciada de aquellos que llegan a los "nuevos destinos" de la migración en Estados Unidos frente a los que se establecen en los "destinos tradicionales"; y la "asimilación geográfica", esto es, si su dispersión en el espacio corresponde con la del grupo dominante mayoritario. Un número más reducido de trabajos se centra en los determinantes de este tipo de movilidad interna. Gurak y Kritz (2000) analizan tres factores que determinan la movilidad interestatal de 24 grupos de inmigrantes de diferentes orígenes nacionales: el capital humano, el capital social y las condiciones económicas del estado de residencia. El capital humano y las condiciones económicas están asociadas a las teorías económicas neoclásicas micro y macro 
ESQUEMA 1

Representación de la movilidad de los mexicanos hacia fuera de los estados de la Unión Americana en los que residían

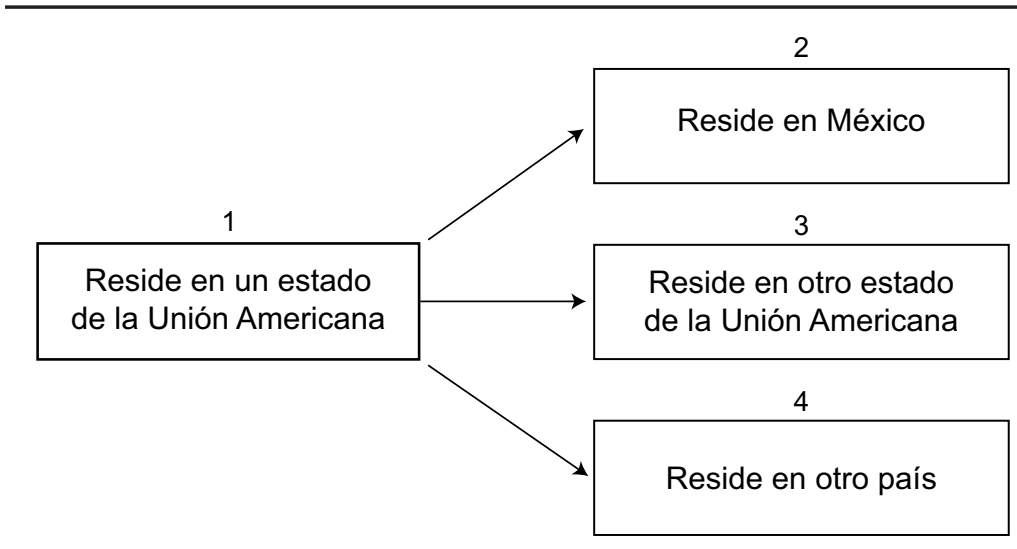

NotA: La movilidad de los mexicanos en Estados Unidos hacia otros terceros países es tan escasa que es excluida de nuestro análisis. Sólo cuatro individuos se van de Estados Unidos con un destino distinto que México (lo que supone menos de seis personas por cada 10000 ).

FUENTE: Elaboración propia.

respectivamente, en particular la ocupación, el crecimiento del empleo, el desempleo y el ingreso per cápita. Por su parte, el capital social está ligado a la teoría de redes sociales.

Es importante mencionar el énfasis analítico que diversos trabajos sobre migración interestatal ponen sobre el estatus de documentación como un aspecto que facilita o inhibe la movilidad interna. En este sentido, Zúñiga y Hernández León (2006) consideran que las regularizaciones tras IRCA (Immigration Reform and Control Act, 1986) posibilitaron la dispersión: una vez en posesión de los documentos que acreditaban su residencia legal, los inmigrantes estuvieron en condiciones de salir de la invisibilidad que les ofrecían los destinos históricos de Los Ángeles, Chicago y Houston, en donde los barrios mexicanos se construyeron en zonas de arribo y refugio de los trabajadores indocumentados (Zuñiga y Hernández León, 2006: 143).

Por otro lado, en una migración básicamente laboral, la ocupación y el tipo de empleo también tendrían una influencia en el patrón de movilidad. Así, por ejemplo, esperaríamos un patrón distinto entre los mexicanos que se ocupan en actividades agrícolas, donde hay una 
mayor propensión a cambiar de lugar de trabajo dependiendo del ciclo de las cosechas. "El trabajador agrícola debe estar dispuesto a seguir el ritmo de las cosechas y tiene que adaptarse a nuevos lugares y ambientes de trabajo. De ahí que la mayoría de los trabajadores agrícolas sean hombres $(80 \%)$ y que viajen solos, sin su familia" (Durand y Massey, 2003: 156). De hecho, existen diferentes rutas por las cuales se mueven los trabajadores agrícolas entre los diferentes estados:

Los jornaleros agrícolas suelen seguir tres circuitos migratorios ancestrales: el del oeste, que va de California a Oregon, Washington y Idaho; el del medio oeste, que surge en Texas y se dirige hacia Wisconsin, Minnesota, Michigan y Ohio; y el circuito de la costa este, que se origina en Florida y se remonta al norte por el rumbo de Georgia, las Carolinas, Virginia, Maryland y Nueva Jersey [Durand y Massey, 2003: 156].

Finalmente, en la mayoría de los artículos sobre movilidad interestatal en Estados Unidos se utilizan métodos estadísticos de diferente clase $^{4}$ y los microdatos de los censos de población de Estados Unidos (Public Use Microdata Sample, PUMS); sin embargo, por las características de los datos utilizados, ninguno de ellos puede incorporar una perspectiva transversal que permita analizar simultáneamente la probabilidad de regresar a México y el patrón de movilidad dentro de Estados Unidos. En este artículo aprovechamos los datos longitudinales del Mexican Migration Project (MMP) para analizar de manera transversal, mediante el análisis de historia de eventos, la dinámica de la movilidad geográfica de los mexicanos que trabajan después de su llegada a Estados Unidos; se consideran los diferentes tipos de movilidad posibles.

La movilidad de retorno ha acaparado la atención de investigadores de ambos lados de la frontera y varios trabajos la describen y analizan (Massey y Espinosa, 1997; Lindstrom, 1996; Massey, Durand y Riosmena, 2006; Fernández Guzmán, 2011). Lindstrom (1996) destaca la importancia de las condiciones económicas de las comunidades de origen para el retorno de los inmigrantes. Massey y Espinosa (1997), en un extenso trabajo sobre la movilidad de los mexicanos hacia Estados Unidos y de retorno, ponen a prueba diversas teorías de la migración internacional; concluyen que la decisión de retornar está confor-

${ }^{4}$ Tablas de frecuencias (Newbold, 1999); modelos de regresión logística (Gurak y Kritz, 2000; Kritz, Gurak y Lee, 2012); modelos de regresión logística multinomial (Nogle, 1997; Kritz, Gurak y Lee, 2012). 
mada básicamente por el siguiente conjunto de factores: la acumulación de capital social y humano, las condiciones de la comunidad de origen, las propiedades (especialmente los terrenos) y los factores de tipo macroeconómico. Massey y Espinosa analizan los factores que explican el retorno separando a los inmigrantes documentados de los indocumentados en dos modelos diferentes, lo que sugiere la importancia de esta característica para entender esta clase de movilidad. Carecer de la documentación legal requerida supone enfrentar diversas dificultades en el proceso de integración en la sociedad de acogida, y eso conduciría a una mayor propensión al retorno; por el contrario, la posesión de documentos legales favorece la integración definitiva en la sociedad de acogida. "La migración de retorno es altamente selectiva con respecto al capital humano específico de la migración. Aquellos migrantes que de alguna manera consiguen obtener documentos legales son, naturalmente, menos inclinados a volver a México" (Massey, Durand y Riosmena, 2006: 111).

En cuanto a la duración de la estancia en Estados Unidos, los trabajos de Lindstrom (1996), Massey y Espinosa (1997) y Massey, Durand y Riosmena (2006), entre otros, muestran que en un número muy elevado los inmigrantes mexicanos pasan uno o dos años en el país vecino y se regresan. No se quiere decir con esto que dicha movilidad sea definitiva: muchos de los que regresan, migrantes de retorno según la definición que se utiliza en este trabajo, ${ }^{5}$ son en un sentido más preciso migrantes circulares, es decir, a lo largo de su vida realizan diversas idas y venidas entre México y Estados Unidos. En contraste, de acuerdo con la teoría de la asimilación, cuánto más tiempo pasa un inmigrante en el país de acogida, más integrado estará con su sociedad y menos incentivos tendrá para el retorno. "Las probabilidades de volver descienden considerablemente a medida que los inmigrantes pasan más tiempo al norte de la frontera" (Massey, Durand y Riosmena, 2006: 111).

Respecto a la migración de retorno, son varios los trabajos que utilizan métodos estadísticos del análisis de historia de eventos mediante los datos longitudinales del MMP. Lindstrom (1996), Massey y Espinosa (1997) y Massey, Durand y Riosmena (2006), entre otros, se basan en las herramientas del análisis de historia de eventos para obtener probabilidades de retornar a México. La novedad de este

${ }^{5}$ En este trabajo se entiende por retorno a la movilidad de los mexicanos que se produce desde Estados Unidos hacia México con independencia del subsiguiente historial migratorio. 
trabajo frente a los anteriores es que utiliza la misma fuente para analizar paralelamente diferentes tipos de movilidad, y no sólo la de regreso a México.

Los patrones de movilidad de retorno e interestatal de los mexicanos en Estados Unidos no se han mantenido constantes a lo largo de la historia; las políticas inmigratorias han ido configurando épocas y fases migratorias (Durand y Massey, 2003; Zolberg, 2006; Alarcón, 2011). En este trabajo se analizan tres épocas: bracero (1942-1964), preIRCA (1965-1985) y post-IRCA (1986-2011). ${ }^{6}$

La época bracero inicia en 1942, cuando Estados Unidos necesitaba mano de obra dada la coyuntura política y económica de la Segunda Guerra Mundial; ante la escasez de fuerza de trabajo, los empleadores del sector agrícola solicitaron a los políticos un acuerdo con México que les proveyese de un mejor acceso a la mano de obra mexicana: el Programa Bracero (acuerdos de este tipo se fueron firmando a lo largo del tiempo hasta su fin en 1964). Durante esa época la migración era principalmente masculina, circular y de origen rural.

Posteriormente, las enmiendas a la Ley de Inmigración y Nacionalidad en 1965 abolieron el sistema basado en cuotas diferentes según los orígenes nacionales y dieron comienzo a la etapa pre-IRCA. Las restricciones para los inmigrantes mexicanos, aún vigentes, y la inercia generada durante la época de los braceros supusieron un incremento sustancial de la inmigración indocumentada. De manera elocuente esta época es denominada también como "la fase de migración indocumentada (1965-1986)" (Durand y Massey, 2003). La enmienda Texas Proviso eximió a los empleadores de cualquier tipo de responsabilidad por contratar inmigrantes indocumentados, por lo que esta práctica continuó realizándose. "Más que una política propiamente dicha, en el caso de la migración mexicana se dio una situación de mantener el status quo, en el que el mercado se encargaba de regular la compraventa de mano de obra migrante y el gobierno americano sólo intervenía de manera esporádica con deportaciones selectivas y ciertos controles fronterizos" (Durand, 2007: 25). Durante este periodo la migración también era masculina, circular y de origen rural, pero ahora se destacaba por su carácter predominantemente indocumentado.

${ }^{6}$ La etapa post-IRCA incluye la crisis económica de 2008. Dado el diseño metodológico de la base de datos utilizada no contamos con suficientes observaciones para distinguir en esta etapa "antes de la crisis" y "después de la crisis". Decidimos conservar las observaciones dado que por su escaso número no modifican las tendencias generales observadas. 
La etapa post-IRCA (1986-2011) comenzó con la Ley de Reforma Inmigratoria y Control de 1986 (IRCA, por sus siglas en inglés) que trató de poner fin al "problema" de la inmigración indocumentada, para lo cual contaba con tres medidas: sanciones para los empleadores, dos programas de amnistía SAW (Special Agricultural Workers) y LAW (Legally Authorized Workers), y nuevos fondos para el fortalecimiento de la frontera. ${ }^{7} \mathrm{El}$ efecto de la reforma no fue el que se pretendía ya que, en primer lugar, fortaleció las redes de los inmigrantes indocumentados al dar residencia permanente a casi tres millones de personas (Alarcón, 2011), y en segundo lugar, la aplicación de las sanciones fue limitada e inadecuada. Para Andreas (2009), el mal funcionamiento de IRCA ayudó a generar la fuerte reacción en contra de la inmigración indocumentada que se produjo en la década siguiente. Además, esta legislación modificó sustancialmente el patrón migratorio, pues ahora son las familias quienes migran, se establecen en el territorio estadounidense, y su origen puede ser rural o urbano. Además, Zúñiga y Hernández (2006) consideran que las regularizaciones posteriores a IRCA posibilitaron una mayor dispersión de la inmigración mexicana.

La Ley de Inmigración de 1990 trató de enfatizar, sin demasiado éxito, la inmigración calificada frente a la reunificación familiar. En esta década comenzaron las políticas de control fronterizo mediante diversas operaciones que disminuyeron en buena medida con la circularidad de los inmigrantes indocumentados. El cruce sin la debida documentación ahora implica costos mucho mayores, tanto en términos económicos como no económicos, lo que ha hecho que este tipo de inmigrantes se quede de manera más permanente en Estados Unidos: la cifra cercana a los seis millones de inmigrantes mexicanos indocumentados en Estados Unidos en 2010 es la mayor de la historia. Se puede decir que a partir de 1994 se abre un proceso de diversificación de los flujos migratorios (Alarcón, 2011); de forma más considerable que antes, resulta imposible referirse a la inmigración como si se tratase de un todo homogéneo. Para el año 2005 sólo un pequeña proporción de la población mexicana que radicaba en Estados Unidos se dedicaba a la agricultura (menos de 6\%); sin embargo, el proceso de mexicanización de la agricultura estaba en su auge: más de dos terceras partes del total de trabajadores agrícolas en Estados Unidos

7 Tuirán y Ávila (2010) denominan al periodo entre 1987 y 2010 como la "era de la militarización de la frontera". 
era mexicano (Giorguli, Gaspar y Leite, 2007: 51 y 91, con base en la Current Population Survey).

El primer objetivo de este trabajo es describir los patrones de movilidad de los hombres mexicanos de 15 años y más en Estados Unidos en cuanto a dirección (migración interestatal o de retorno), duración (tiempo de residencia en dicho estado desde que obtuvieron el primer empleo) y épocas de la migración (bracero, pre-IRCA y post-IRCA).

El segundo objetivo es analizar cómo el estatus de documentación, la ocupación en la agricultura y las condiciones macroeconómicas influyen en cada una de las direcciones en competencia; a la par otros factores son utilizados como variables de control. De este modo se tienen en cuenta los factores que la literatura sugiere como los más importantes para explicar las movilidades laborales referidas en el repaso de las investigaciones sobre migración interestatal y de retorno. ${ }^{8}$ Comparar si los efectos de las variables sobre los flujos son iguales o diferenciados es útil en la medida en que es en la comparación donde se puede apreciar mejor la esencia de cada uno de ellos (como por ejemplo, en el trabajo de Lindstrom y Lauster, 2001, donde se comparan las opciones de migración interna e internacional de los zacatecanos).

De acuerdo con lo anteriormente expuesto, se enumeran algunos de los resultados esperados del análisis: 1) Que la movilidad de retorno se produzca con intensidad en los primeros años y vaya disminuyendo conforme avanza el tiempo. 2) Que el estatus indocumentado del inmigrante reduzca la movilidad interestatal pero suponga una mayor movilidad de retorno respecto de los documentados. Aunque el carecer de documentos puede influir de manera significativamente distinta en cada una de las épocas de la migración, dado que las políticas varían en el tiempo en cuanto a su dureza y aplicación. 3) Que los inmigrantes ocupados en la agricultura tengan una mayor movilidad interestatal. 4) Que los factores macroeconómicos repercutan de manera significativa en el retorno, en específico, un menor desempleo en Estados Unidos supondrá una menor movilidad de retorno, y por el contrario, los incrementos en los ingresos por persona (PIB per cápita)

${ }^{8}$ Con la única ausencia de los factores de capital social y teoría de redes que quedará pendiente para futuros trabajos. Los indicadores de redes sociales tradicionalmente utilizados se refieren a la experiencia migratoria de otros familiares (padre, madre, hermanos, entre otros) y sirven para explicar una primera migración. Para el retorno o la movilidad dentro de Estados Unidos se requerirían probablemente otros indicadores de redes sociales tales como familiares en otros estados de la Unión Americana, retorno anticipado de algún familiar, entre otros. Este es un tema sobre el cual se puede desarrollar más investigación en el futuro. 
en México se relacionen con una mayor movilidad de regreso al país. 5) Que las movilidades de retorno e interestatal sean sensiblemente menores en la última época de la migración, dado que las políticas migratorias afectarán en mayor medida a la población inmigrante indocumentada.

\section{Fuentes y descripción breve de los datos usados}

La fuente que se utiliza en este trabajo es el Mexican Migration Project (MMP). Desde 1982, con periodicidad anual, se entrevista mediante la etnoencuesta a familias de ciertas comunidades distribuidas a lo largo de México. Los datos se completan con los de los hogares de los migrantes en Estados Unidos. A diferencia de la encuesta levantada en México, que es aleatoria dentro de las comunidades, la realizada en Estados Unidos sigue la técnica de bola de nieve. Los hogares encuestados en la Unión Americana suman $10 \%$ de la población encuestada en México.

El MMP genera datos demográficos, migratorios y laborales para todos los miembros del hogar y de la familia. A todos los jefes de familia se les realiza una historia de vida completa que incluye una historia migratoria. La encuesta es levantada en invierno cuando se considera que existe más probabilidad de que los inmigrantes estén en México de vacaciones. De toda la información que ofrece la MMP, en este trabajo se utilizará la relativa a los varones en el archivo Life.

Esta base de datos registra años-persona vividos y suma un total de 1082322 años-persona. En esta investigación, la cifra de años-persona vividos se reduce aproximadamente a 16000 para el análisis descriptivo y el análisis multivariado, ya que nuestro universo está conformado por hombres mayores de 14 años que tuvieron al menos una migración laboral a Estados Unidos. Tomamos los años-persona desde el primer empleo en Estados Unidos hasta que experimenta el evento (movilidad interestatal o de retorno), con una ventana de observación de cinco años en ambos casos. El estudio se circunscribe a estos primeros años porque es donde se concentra la inmensa mayoría de los eventos. ${ }^{9} \mathrm{Se}$ hace notar que la entrada en el primer empleo en Estados Unidos coincide con el año de la primera migración hacia ese país.

${ }^{9}$ Durante los cinco primeros años se producen más del $85 \%$ de eventos tanto de retorno como de migración interestatal (se eliminan todos los años-persona vividos que quedan más allá de la ventana de observación). 
El MMP incluye tanto a personas encuestadas en México como a las personas encuestadas en Estados Unidos. A pesar de no ser una muestra representativa nacional, análisis anteriores han dado cuenta de que la base de datos está conformada por una muestra con características sociodemográficas básicas similares a las obtenidas de encuestas con representatividad nacional (Zenteno y Massey, 1999). Sin embargo, en este análisis se presenta como limitante el que debimos concentrarnos en los jefes de hogar. Se excluye por lo tanto la migración de otros adultos miembros del hogar como el o la cónyuge, hermanos o hijos mayores.

Complementariamente, los datos macroeconómicos se obtienen del archivo Natlyear del MMP y de dos trabajos que analizan series históricas de datos macroeconómicos para México (Aparicio Cabrera, 2011) y Estados Unidos ${ }^{10}$ (Bureau of Labor Statistics, 2013).

\section{Metodología}

Para la consecución de los objetivos propuestos, primero se llevó a cabo un análisis descriptivo de los patrones de movilidad de los hombres mexicanos de 15 años y más en Estados Unidos en cuanto a dirección (migración interestatal o de retorno), duración (tiempo de residencia en dicho estado desde que obtuvieron el primer empleo) y épocas de la migración (bracero, pre-IRCA y post-IRCA). El inicio del tiempo de exposición comienza cuando una persona nacida en México inicia su primer año de trabajo en Estados Unidos; termina cuando se produce una transición entre estados, que de no haberse producido en el momento de la entrevista sería considerado censor o en su caso cuando hayan pasado los cinco años de observación.

En segundo lugar se llevó a cabo un modelo logístico multinomial ${ }^{11}$ en tiempo discreto de la primera movilidad tras haber entrado en el mercado laboral de Estados Unidos (que coincide en casi la totalidad de los casos con la primera residencia en el país del norte). La variable dependiente de este trabajo se compone de tres categorías: se permanece en el estado, hay movilidad interestatal, o se produce la migración de retorno. ${ }^{12}$

${ }^{10}$ Los datos de desempleo en Estados Unidos anteriores y posteriores a 1948 no son estrictamente comparables: antes de 1948 se tienen en cuenta los de 14 años y más, y después de 1947 los de 16 y más. Sin embargo se entiende que en el análisis que aquí se expone no supone una diferencia significativa.

${ }^{11}$ Dado que se trata de dos riesgos en competencia es necesario un modelo que permita diversas respuestas posibles (retornó, migró internamente y permaneció).

${ }^{12}$ La variable JOBSTATE del MMP recoge para cada año el estado de la Unión Ame- 
En este modelo se prueban los efectos de ser o no indocumentado (INDOCU) y de la ocupación o no en la agricultura (AGRI), así como de dos variables macroeconómicas: el desempleo en Estados Unidos (DESUSA) y la tasa de variación anual en el producto interior bruto per cápita en México en dólares de 1980 (VARMEX). Las cuatro variables son rezagadas un año con el fin de minimizar posibles problemas de endogeneidad.

Las variables de control utilizadas son la edad (EDAD, en años y en años al cuadrado),$^{13}$ la educación (EDU, no asistió, primaria incompleta y primaria completa y más), estado civil (CIVIL, casado o soltero), la época de la migración (EPOCA, programa bracero, 1942-1964; pre-IRCA, 1965-1985; o post-IRCA, 1986-2011), el estado de residencia en territorio estadounidense (RES, California, Texas y el resto de estados) ${ }^{14}$ y la duración (DUR, de uno a cinco años ${ }^{15}$ desde el primer empleo en Estados Unidos, que para la inmensa mayoría es igual al tiempo desde la llegada a Estados Unidos). Todas aquellas variables que varían en el tiempo han sido rezagadas un periodo para reducir problemas de endogeneidad.

El modelo logístico multinomial se compone de dos modelos logísticos estimados simultáneamente (uno para la movilidad interna y otro para la movilidad de retorno):

$$
\begin{aligned}
& \text { Modelo 1: } \ln \left[\frac{p_{m i}(x)}{p_{p}(x)}\right]=\beta_{0,1}+\beta_{1,1} D U R+\beta_{2,1} E D A D+\beta_{3,1} C I V I L+\beta_{4,1} E D U+ \\
& +\beta_{5,1} R E S+\beta_{6,1} E P O C A+\beta_{7,1} A G R I+\beta_{8,1} I N D O C U+ \\
& +\beta_{9,1} \text { DESUSA }+\beta_{10,1} \text { VARMEX }
\end{aligned}
$$

ricana (o en su caso, otro país) donde se trabaja. En esta investigación se asume que el estado donde se trabaja es aquél donde se reside.

${ }^{13}$ La literatura coincide en que la relación entre la edad y la probabilidad de migrar debe ser modelizada de forma cuadrática (entre otros, Massey y Espinosa, 1997; Massey, Durand y Riosmena, 2006).

14 Todas las variables de control se utilizan tradicionalmente en los modelos de movilidad geográfica (véase, por ejemplo, Massey y Espinosa, 1997). La única variable diferente en nuestro análisis es la de estado de residencia en Estados Unidos. Asumimos que los patrones de movilidad interna y de retorno de los migrantes mexicanos no serán los mismos dependiendo del estado habitual de residencia. Esperaríamos menor movilidad interna e internacional en los estados con mayor tradición y presencia de migración mexicana, donde las redes sociales están más consolidadas y puede haber una comunidad de mexicanos más establecida. En ese sentido esperamos que en California haya menos movilidad, después en Texas y, finalmente en el resto de los estados.

${ }^{15}$ La duración se modeliza mediante una forma funcional cuadrática dado que es la forma más parsimoniosa y que es capaz de comprender cabalmente a ambos riesgos en competencia. 


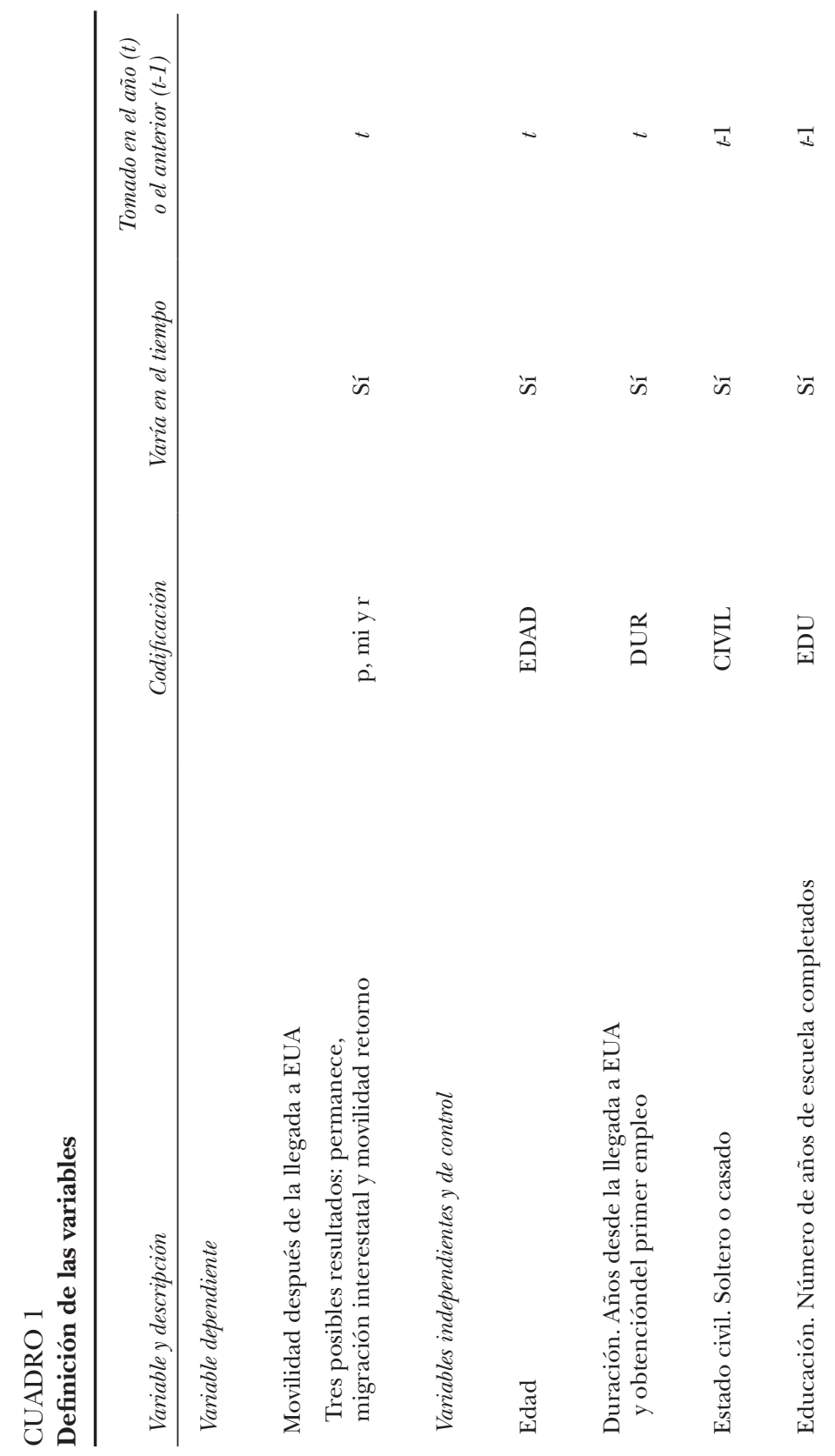




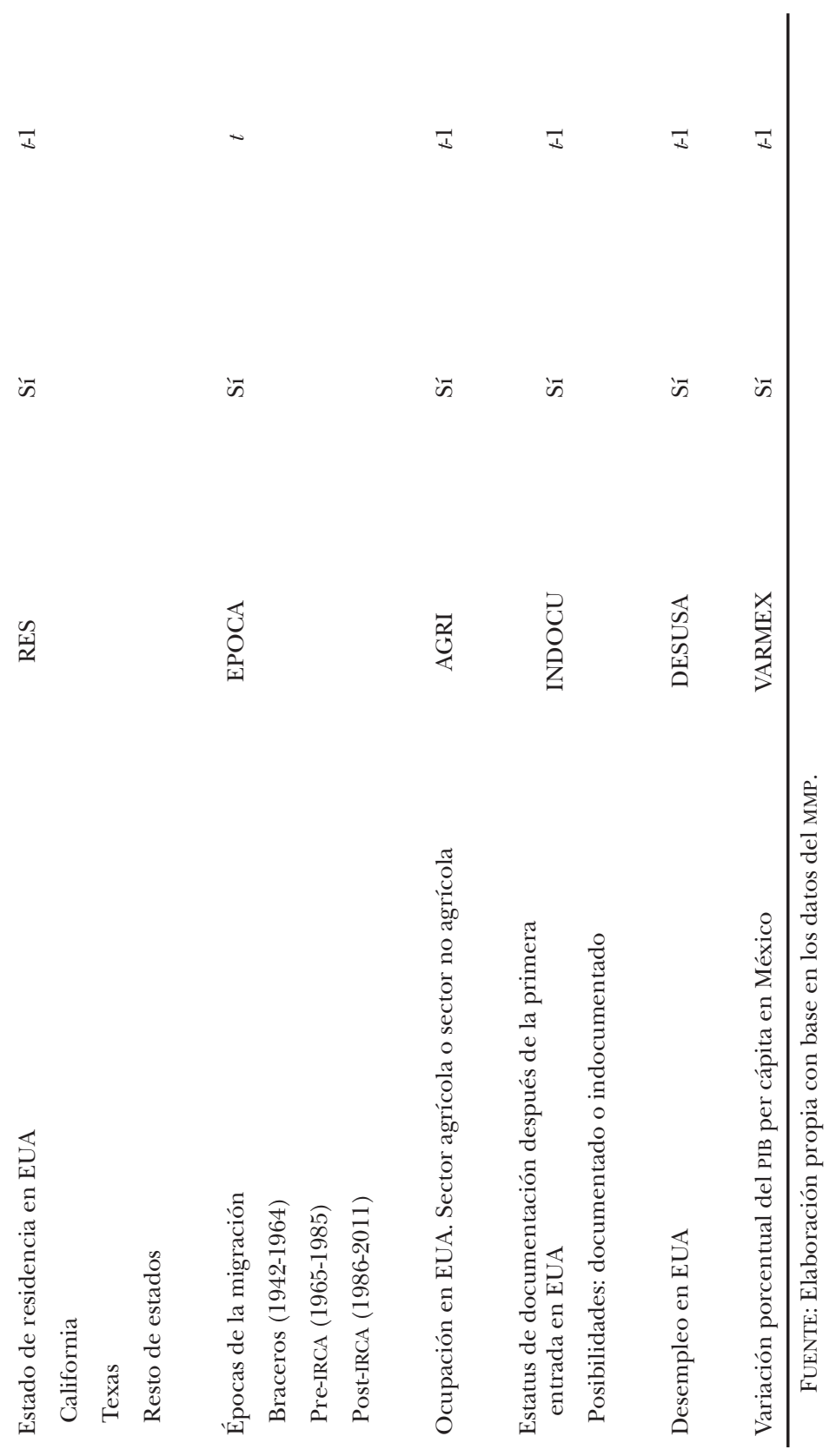




$$
\begin{aligned}
& \text { Modelo 3: } \ln \left[\frac{p_{r}(x)}{p_{p}(x)}\right]=\beta_{0,2}+\beta_{1,2} D U R+\beta_{2,2} E D A D+\beta_{3,2} C I V I L+\beta_{4,2} E D U+ \\
& +\beta_{5,2} R E S+\beta_{6,2} E P O C A+\beta_{7,2} A G R I+\beta_{8,2} I N D O C U+ \\
& +\beta_{9,2} \text { DESUSA }+\beta_{10,2} \text { VARMEX }
\end{aligned}
$$

La categoría de referencia es permanecer en el estado $(p)$, mientras que las dos categorías en competencia son la movilidad interestatal ( mi) y la movilidad de retorno $(r)$. Las variables que se han de tener en cuenta en ambos modelos son las mismas, sin embargo, los coeficientes estimados para cada una de ellas pueden diferir (incluso en la constante).

Se quiere analizar si el efecto del estatus de documentación está mediado de alguna manera por las épocas de la migración, por lo que se establece una interacción entre ambas. De esta interacción resultan los siguientes dos modelos logísticos a estimar simultáneamente:

$$
\begin{aligned}
& \text { Modelo 2: } \ln \left[\frac{p_{m i}(x)}{p_{p}(x)}\right]=\text { Modelo } 1+\beta_{11,1}(\text { EPOCA X INDOCU }) \\
& \text { Modelo 4: } \ln \left[\frac{p_{r}(x)}{p_{p}(x)}\right]=\text { Modelo } 3+\beta_{11,2}(\text { EPOCA X INDOCU })
\end{aligned}
$$

También se probó la interacción entre la agricultura y las épocas de la migración pero resultaron no significativas para la migración interestatal. Esto es, los efectos de la agricultura no varían entre las diferentes épocas de la migración en lo que respecta a la propensión a la migración interestatal frente a la permanencia.

\section{Resultados y análisis}

\section{Análisis descriptivo}

En la gráfica 1 se exponen las diferentes probabilidades para las movilidades interestatal y de retorno de los varones mexicanos en Estados Unidos en función de la duración (años transcurridos desde la llegada a dicho país). Por su parte, en la gráfica 2 se desagregan las curvas an- 


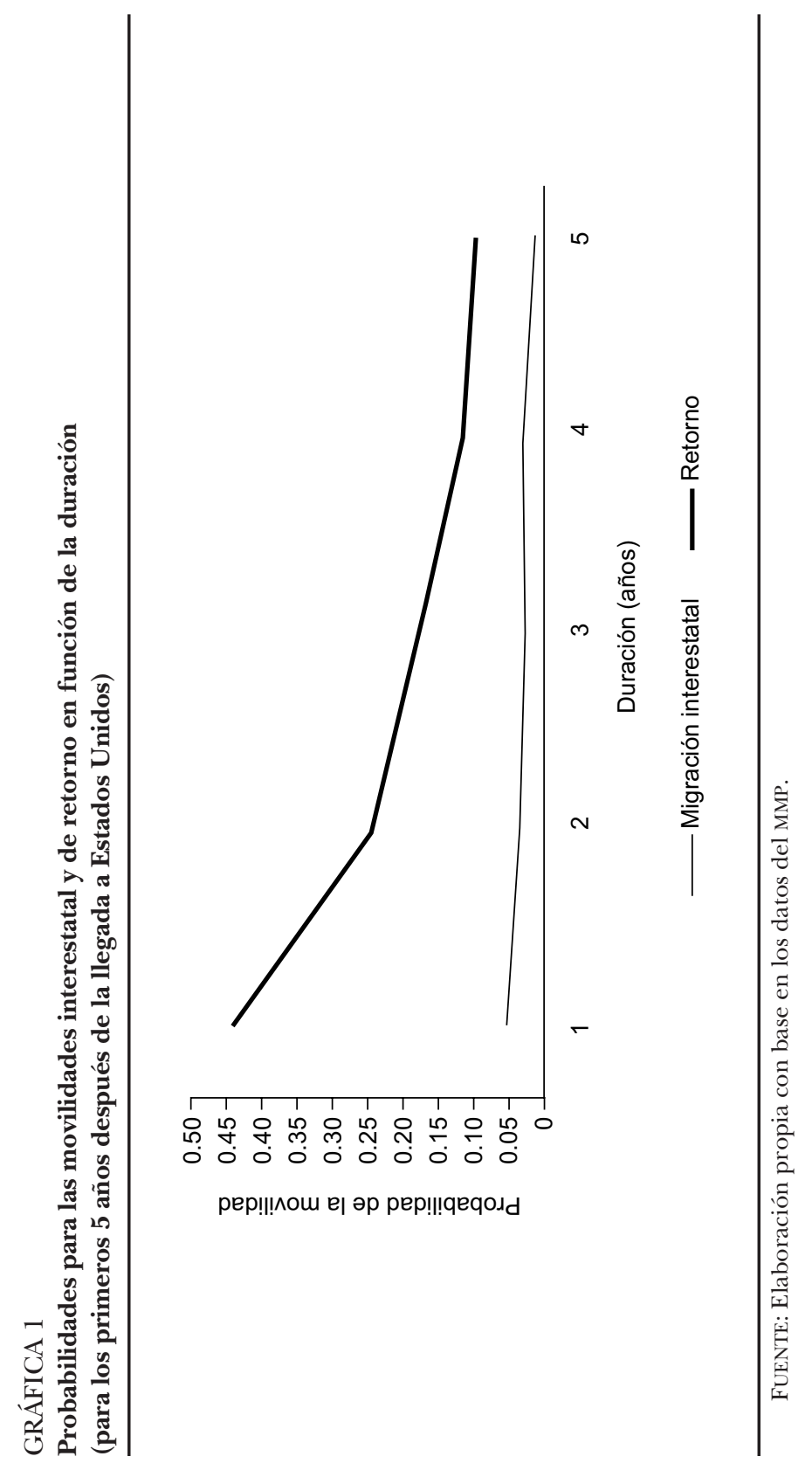




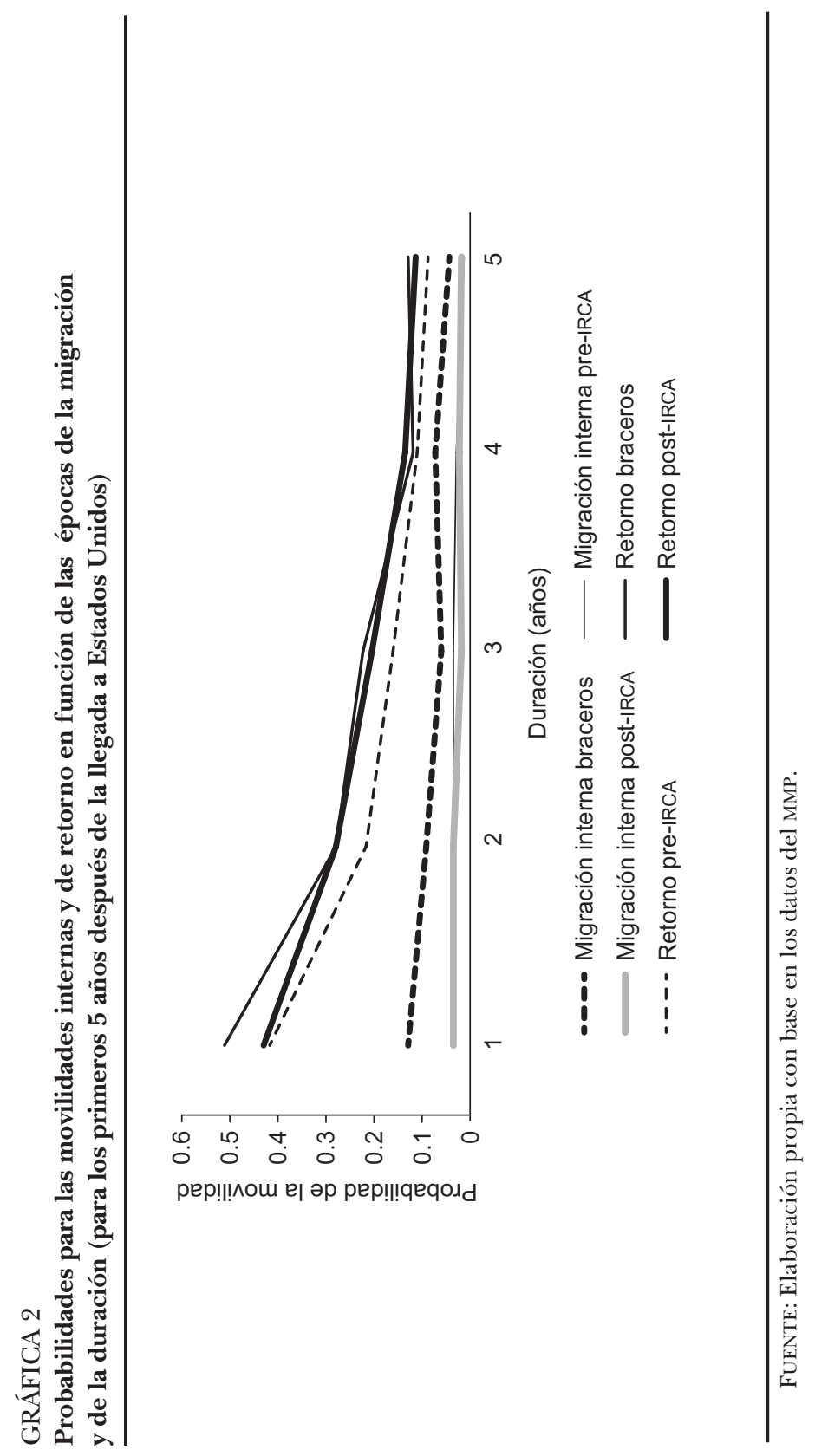


teriores en las diferentes épocas de la migración bajo estudio. Respecto a la movilidad de retorno, agregando todas las fases se puede apreciar que las probabilidades son muy elevadas al comienzo (especialmente el primer año) y cómo descienden de manera rápida. En el caso de la movilidad interestatal también en los primeros años se producen las mayores probabilidades de movilidad para luego descender; pero dicho descenso es mucho menos pronunciado que en el caso del retorno, y la probabilidad se mantiene prácticamente constante después del segundo año. Destaca también para todos los años que las probabilidades de retorno son notablemente mayores a las probabilidades de migrar internamente en Estados Unidos.

En cuanto a la movilidad de retorno, al analizar las diferencias entre las etapas se aprecia que durante la época de los braceros la probabilidad de movilidad del primer año (0.5) es mayor que la de retorno pre-IRCA (0.4). Sin embargo en el resto de las duraciones las probabilidades de la época bracero y post-IRCA se asemejan bastante. Pre-IRCA es la época de la migración donde las probabilidades de retornar son menores en cada uno de los cinco años.

En el caso de la movilidad interestatal, nuevamente la época bracero resulta la poseedora de una mayor movilidad, especialmente durante el primer año donde la diferencia es mayor. Las formas que adquieren las probabilidades de movilidad interestatal en cada una de las etapas difieren. En la época bracero el ajuste que se podría realizar es una función lineal descendente. Por su parte, en las épocas pre-IRCA y post-IRCA tienen la forma de una constante, esto es, conforme avanza el tiempo las probabilidades de migrar se mantienen iguales. Además ambas son realmente semejantes. La línea agregada con las tres épocas (gráfica 1) se ve especialmente influenciada por la forma del periodo de los braceros.

En las gráficas 3 y 4 se presentan respectivamente las funciones de sobrevivencia para todas las etapas de manera conjunta y para cada una de ellas por separado. La movilidad de retorno es un fenómeno mayoritario que se extingue de manera relativamente rápida en el tiempo. Para ilustrar ambos hechos baste con mencionar que en cinco años siete de cada diez personas han experimentado el evento, y que en tan sólo dos años, aproximadamente seis de cada diez regresan a México. Contrastantemente la movilidad interestatal es un fenómeno que experimenta un número de población significativamente menor a lo largo de todo el periodo de observación y cuya extinción en el tiempo es relativamente lenta. En cinco años no se alcanza la cifra de que dos de cada diez personas hayan experimentado el evento. 


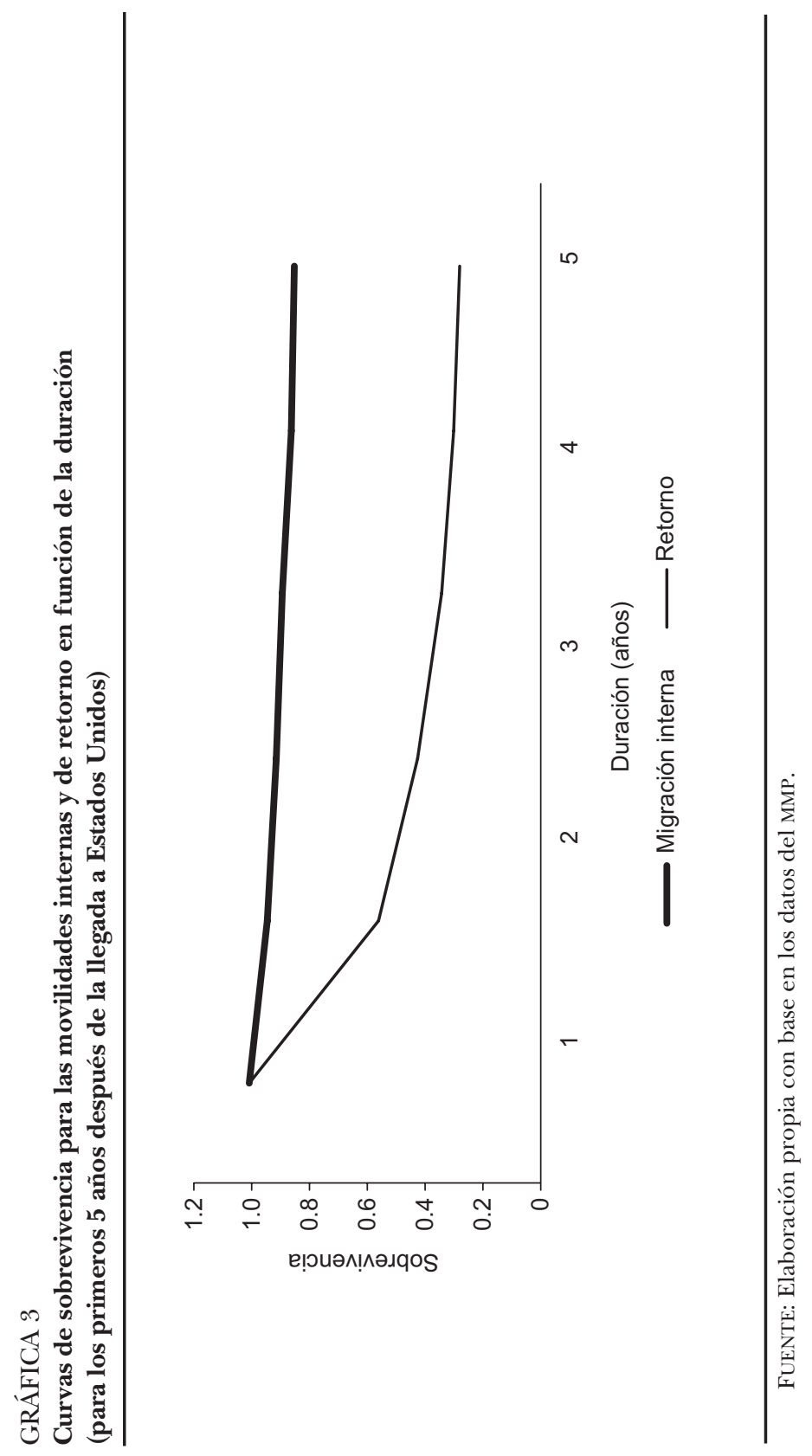




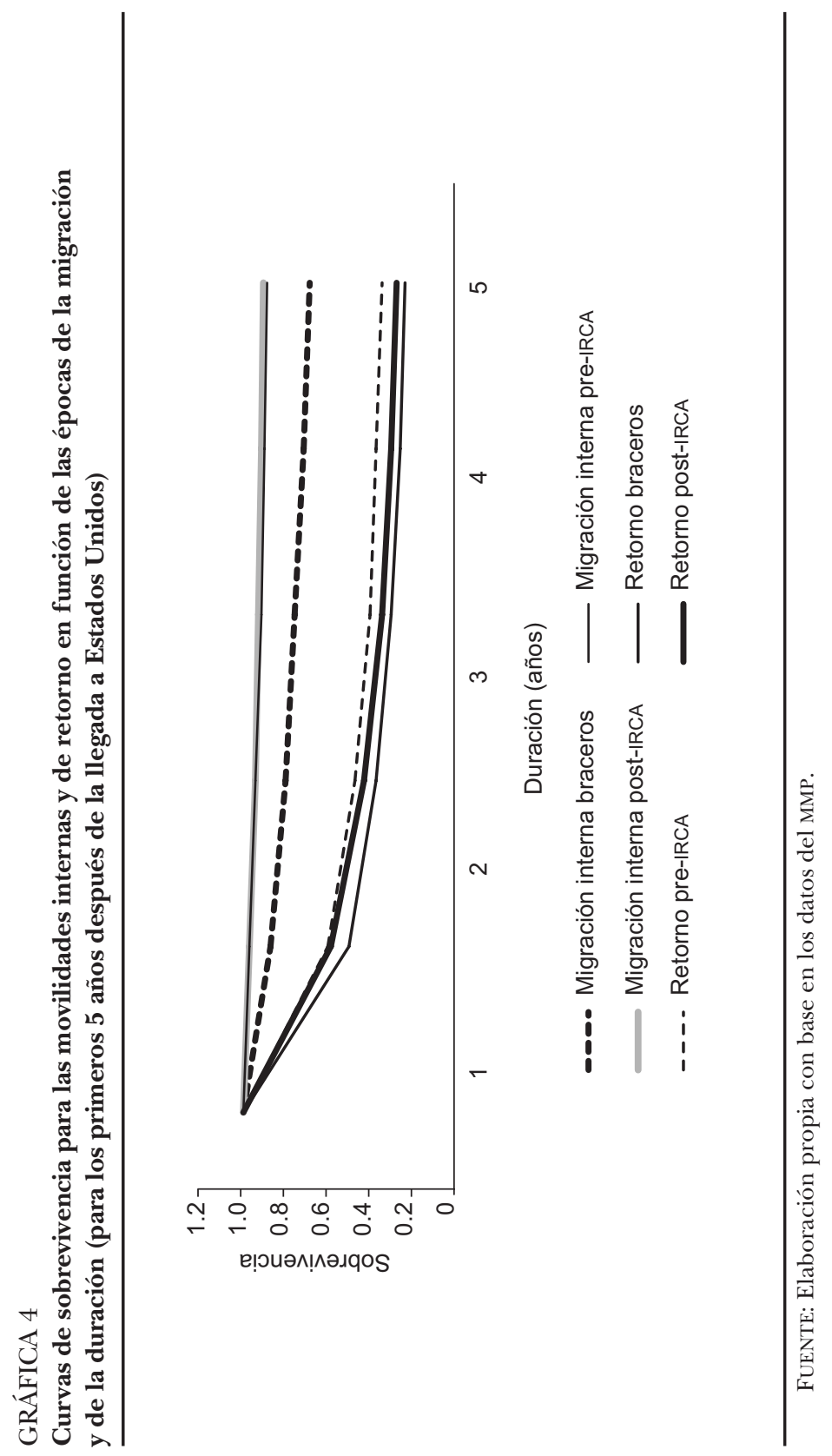


Cuando las curvas de sobrevivencia se desagregan por etapas de la migración, evidencian gráficamente algunas de las conclusiones a las que se llegó con la lectura de las gráficas 1 y 2. La movilidad interestatal durante la época bracero destaca muy ampliamente desde las épocas pre-IRCA y post-IRCA, las cuales son prácticamente idénticas. La movilidad de retorno en la época bracero destaca en el primer año respecto a pre-IRCA y post-IRCA. Y mientras la época pre-IRCA se mantiene paralela a braceros, la post-IRCA parece mostrar una ligera convergencia con la época bracero.

Hasta aquí, el análisis descriptivo muestra que los patrones de movilidad efectivamente varían dependiendo del periodo. Nuestro análisis sugiere que la época bracero es la de mayor movilidad tanto interna como de retorno entre los varones migrantes. Esto seguramente corresponde, parcialmente, con el carácter circular y altamente agrícola de la migración masculina, así como con el mayor carácter documentado de la migración en esta etapa, lo que facilita ambas formas de movilidad. El análisis multivariado nos permitirá analizar si las diferencias se explican por estos tres factores o si, incluso después de controlar por los mismos, el patrón de movilidad difiere entre las épocas de la migración.

\section{Resultados del análisis multivariado}

Los cuadros 2 y 3 recogen las variables utilizadas en el análisis multivariado. En el primero de ellos resalta el predomino de jóvenes y de adultos jóvenes de 15 a 30 años; tres de cada cuatro de los varones en la muestra caen en este rango de edad en el momento de entrar por primera vez a Estados Unidos. En cuanto a su estado civil, se dividen prácticamente a la mitad, casados y solteros. La agricultura es un sector de ocupación que por sí solo supone $46 \%$ de los empleos de los mexicanos en Estados Unidos. Siete de cada diez individuos en la encuesta partieron como indocumentados y casi la mitad no había completado la primaria. La época de la migración que más representada está en la muestra del MMP es pre-IRCA (seguida de post-IRCA y bracero).

El cuadro 3 muestra con detalle los fenómenos de la indocumentación y de la ocupación en la agricultura a lo largo de las épocas de la migración, tanto en términos relativos como absolutos. Si bien son características que están muy presentes durante las tres épocas analizadas, su peso ha ido cambiando a lo largo del tiempo. 


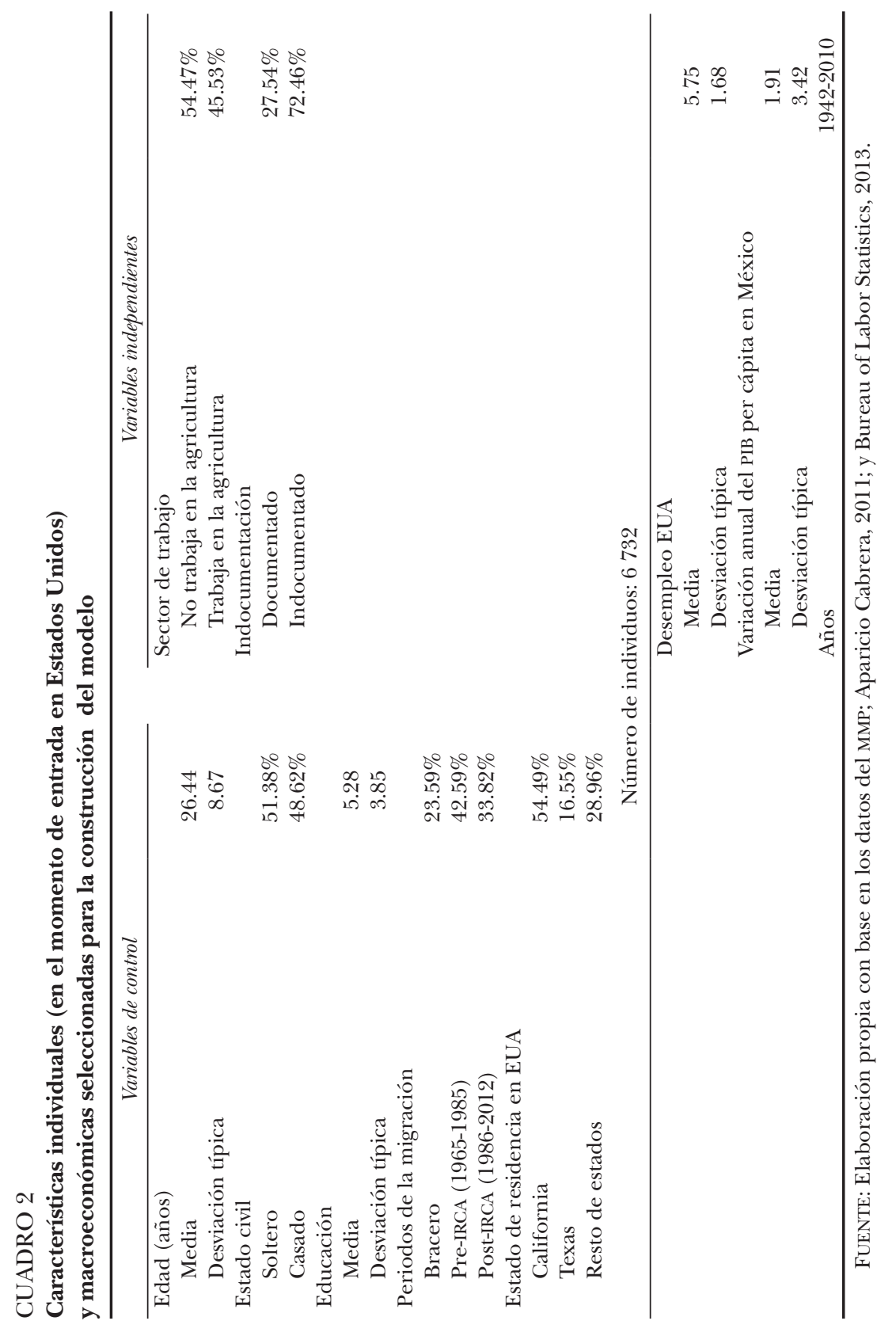




\section{CUADRO 3}

Indocumentación y ocupación en la agricultura según las épocas de la migración en el primer año en Estados Unidos (en número de personas y términos relativos)

\begin{tabular}{lrrrr}
\hline & Bracero & Pre-IRCA & Post-IRCA & $\begin{array}{c}\text { Todas } \\
\text { las etapas }\end{array}$ \\
\hline Documentación & & & & \\
Documentados & 1096 & 397 & 361 & 1854 \\
Indocumentados & $69.0 \%$ & $13.8 \%$ & $15.8 \%$ & $27.5 \%$ \\
& 492 & 2475 & 1925 & 4878 \\
Ocupación & $31.0 \%$ & $86.2 \%$ & $84.2 \%$ & $72.5 \%$ \\
No agricultura & & & & \\
Agricultura & 230 & 1677 & 1760 & 3667 \\
& $14.5 \%$ & $58.5 \%$ & $77.3 \%$ & $54.5 \%$ \\
Total individuos & 1358 & 1190 & 517 & 3065 \\
\hline
\end{tabular}

FUENTE: Elaboración propia con base en los datos del MMP.

El porcentaje de indocumentación en la muestra del MMP para la época bracero es de aproximadamente $31 \%$. Durante el periodo preIRCA este porcentaje se eleva considerablemente hasta más de $86 \%$, y sólo se verá reducido ligeramente durante la época post-IRCA. Hay que tener en cuenta que este dato se refiere a la situación de documentación al ingresar a Estados Unidos y no refleja la posible obtención de documentos en los años sucesivos.

En un proceso casi a la inversa, en la población encuestada que está constituida en su mayoría por migrantes de retorno, el estar ocupado en la agricultura disminuyó a la mitad aproximadamente en cada época de la migración. En la de los braceros la gran mayoría de los inmigrantes se dedicaba a la agricultura, mientras que en la post-IRCA menos de una cuarta parte de los mexicanos se dedicó a la agricultura. Esto sucede sin menoscabo del proceso de mexicanización de la agricultura estadounidense, es decir, aunque disminuye el peso relativo de 
los mexicanos ocupados en actividades agrícolas respecto de otras ocupaciones, los mexicanos siguen teniendo una participación importante dentro del sector agrícola en Estados Unidos (37.9\% del total de trabajadores agrícolas en 2005; Giorguli, Gaspar y Leite, 2007: 51).

El cuadro 4 muestra los parámetros estimados de un modelo logístico multinomial que predice la primera movilidad de los hombres mexicanos hacia fuera del estado en que residían. Mediante éste se pueden analizar los efectos que las diversas variables tienen sobre las probabilidades y propensiones a la movilidad interestatal entre estados de la Unión Americana o a la movilidad de retorno hacia México. ${ }^{16}$

Estar casado supone una propensión a la movilidad hacia México frente a permanecer en el estado en el que se residía (una cuarta parte más que los solteros; se controla por las demás variables). Esto se puede deber a las parejas que se separan cuando se produce la migración internacional y que supone un poderoso aliciente para el retorno. El caso de la movilidad interestatal no es estadísticamente significativo.

La propensión a la movilidad tanto interestatal como de retorno va disminuyendo por cada año de educación que la persona posee (se controla por el resto de variables). Esto es, a más educación menor movilidad.

El estado de residencia supone diferencias importantes en cuanto a la movilidad, y evidencia factores que la influyen como las redes sociales, el capital social y la asimilación. La propensión a la movilidad interestatal en Texas o en el "resto de estados" con respecto a California es de una magnitud superior a dos veces y media (se controla por el resto de variables). En lo que se refiere a la movilidad de retorno la propensión de los mexicanos en Texas es 55\% mayor que las de los que residen en California, mientras que en el "resto de estados" es casi 13\% mayor. A lo largo de la historia de la migración de México a Estados Unidos el estado de California se ha erigido en el principal enclave de la población mexicana que ofrece protección, empleo y diversas posibilidades de integración a la cultura estadounidense; es por ello que probablemente los inmigrantes con este destino son más propensos a quedarse en el territorio de dicho estado, especialmente en lo que respecta a la movilidad interestatal.

${ }^{16}$ En el cuadro 4 se muestran los coeficientes que resultan de la estimación del modelo logístico multinomial. A lo largo del texto analizamos las razones de momios, es decir el exponencial del coeficiente. Esta transformación facilita la interpretación de los datos al referirse a cambios en la propensión de ocurrencia respecto de la categoría de referencia. 


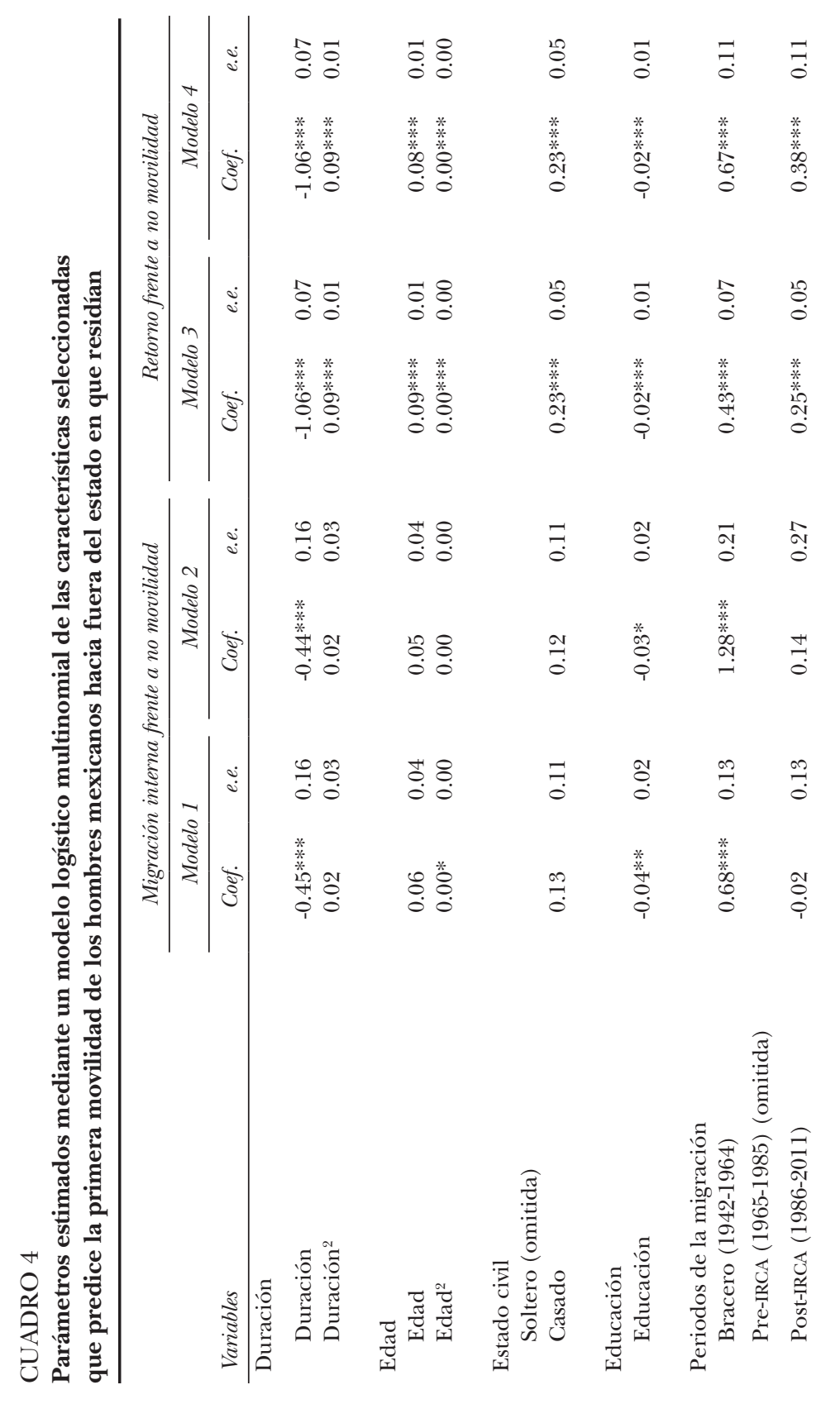




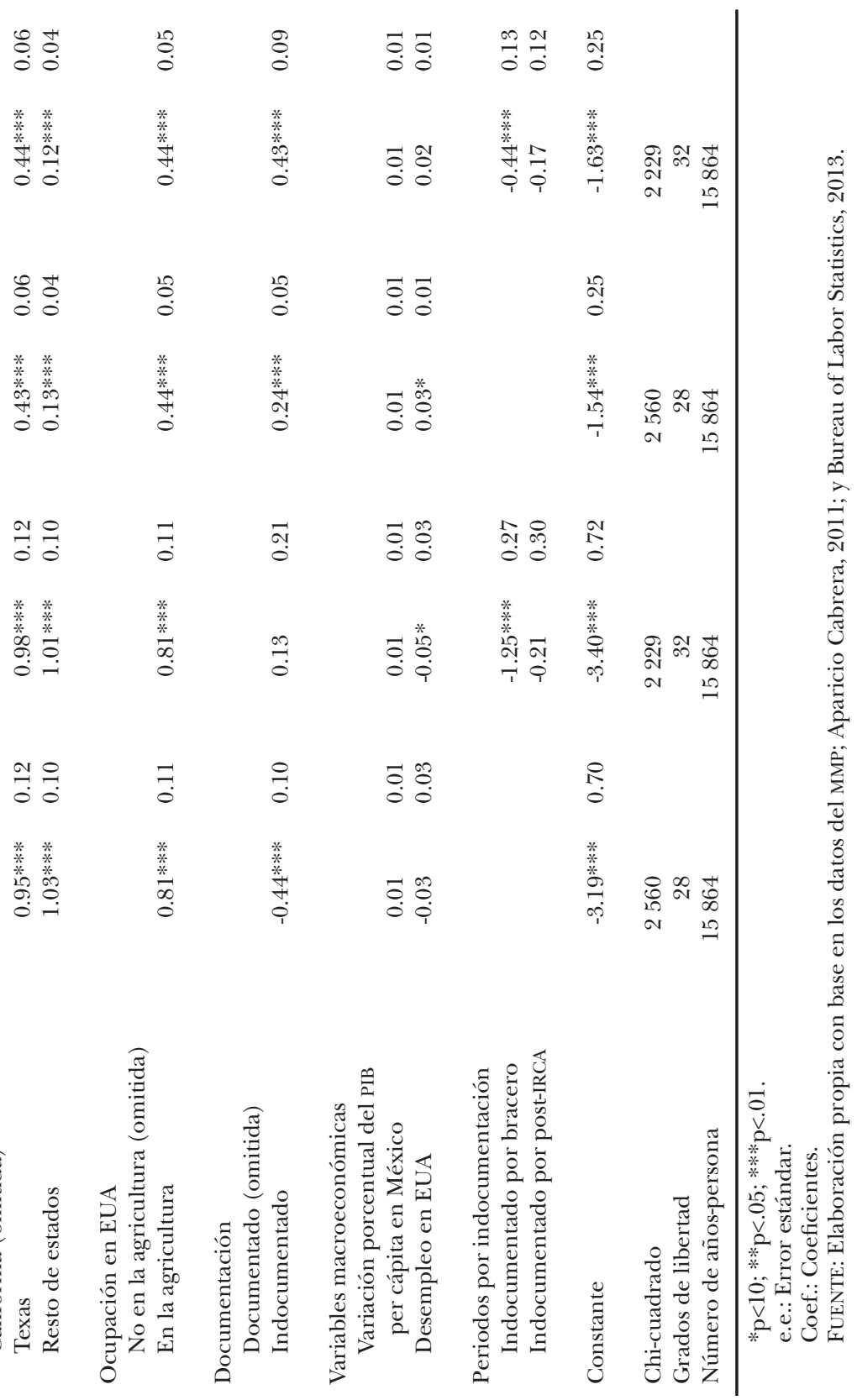


La ocupación en la agricultura y el estatus de indocumentación suponen los dos ejes principales de este trabajo junto con las variables macroeconómicas. En los siguientes párrafos se llevará a cabo la lectura y el análisis de todas ellas. El análisis de la variable indocumentación se debe de hacer conjuntamente con la de las etapas de la inmigración puesto que se ha llevado a cabo una interacción entre ambas.

El aumento del desempleo en Estados Unidos y el incremento porcentual del PIB per cápita en México resultaron no ser estadísticamente significativos para el retorno, por lo que no se encuentra evidencia estadística que apoye las hipótesis previamente expresadas al respecto. Por su parte, para la migración interna sólo fue significativo estadísticamente (al 10\%) el incremento del desempleo en Estados Unidos (por cada aumento en $1 \%$ en la tasa de desempleo, la propensión a migrar internamente disminuye en casi 5 por ciento).

En lo que respecta a la indocumentación, existen dos tipos de lecturas posibles. En primer lugar se puede comparar lo que significa ser documentado respecto a ser indocumentado en cada una de las épocas de la migración. En segundo lugar podemos comparar entre las distintas épocas para cada estatus de documentación, esto es, lo que significa ser documentado o indocumentado en una época con lo que supone en otra. Los cuadros 5 y 6 recogen ambas lecturas posibles para la movilidad interestatal y para la de retorno.

De acuerdo con el cuadro 5 se puede concluir que los indocumentados tienen menor propensión a la movilidad interestatal respecto a la permanencia que los documentados en la época de bracero (se controla por el resto de variables). Sin embargo, ser indocumentado no supone ninguna diferencia respecto a ser documentado en cuanto a la migración interna en las épocas de pre-IRCA y post-IRCA. El hecho de que en la época de los braceros sea donde haya mayor diferencia entre indocumentados y documentados ( $51 \%$ menor propensión en los indocumentados), no significa que la movilidad de los indocumentados en dicha época sea menor respecto a la de otras épocas. Si comparamos a los documentados de la época bracero frente a los de preIRCA, su propensión a la movilidad interestatal frente a la permanencia en el estado en el que residían se acerca al cuádruple; y en el caso de los indocumentados no hay evidencia estadística de que sea diferente. Finalmente, no hay diferencias estadísticamente significativas si se realiza el mismo tipo de comparaciones entre pre-IRCA y post-IRCA.

El cuadro 6 permite observar qué ocurre en el caso de la movilidad de retorno. El ser indocumentado frente a ser documentado supone 


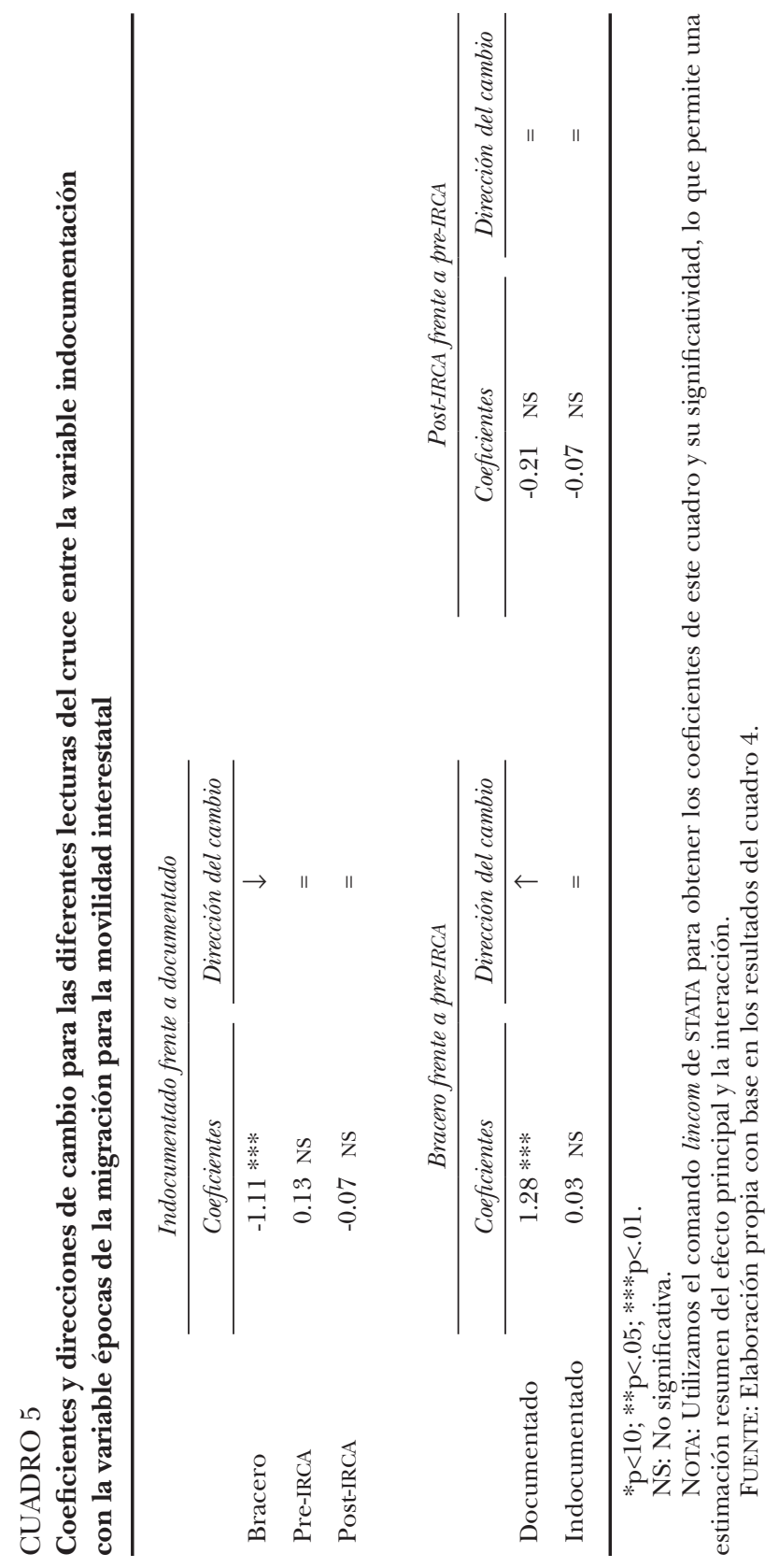




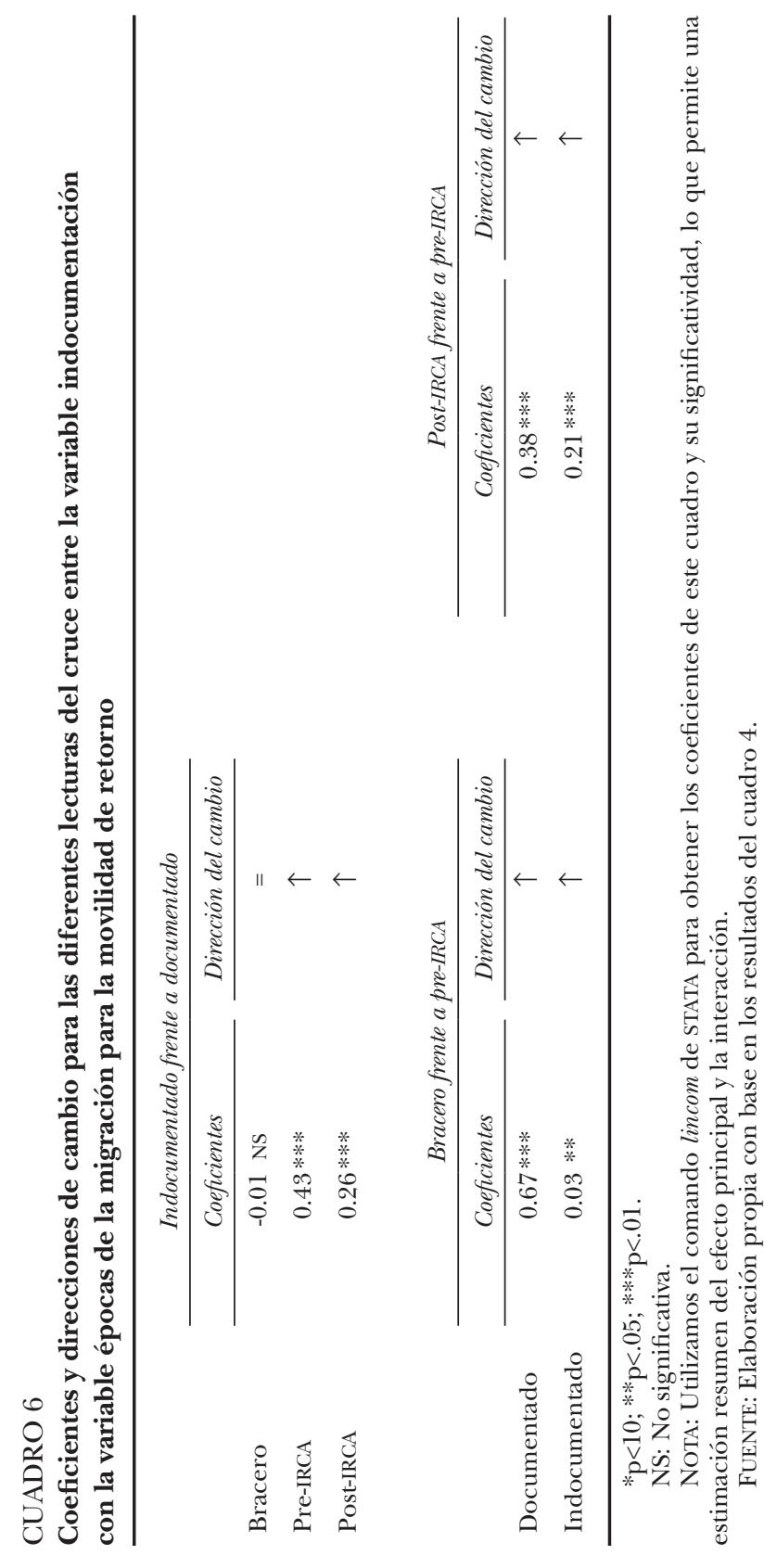


una propensión aproximadamente $54 \%$ mayor al retorno frente a la permanencia durante pre-IRCA. Mientras que en post-IRCA ser indocumentado supone también una mayor propensión a la movilidad de retorno, pero menor que en pre-IRCA, y en bracero no hay evidencia estadística que muestre una diferencia.

Si comparamos a documentados de la época de braceros frente a los de pre-IRCA, su propensión a la movilidad de retorno frente a la permanencia en el estado en que residían es casi el doble. Y si se compara la movilidad de los indocumentados entre dichas épocas, la diferencia entre propensiones es $26 \%$ mayor en el caso de los braceros. $\mathrm{Si}$ se realiza el mismo tipo de comparaciones entre las épocas pre-IRCA y post-IRCA se encuentra que para los documentados la propensión es $46 \%$ mayor en post-IRCA y para los indocumentados es $23 \%$ mayor en post-IRCA.

Con base en los resultados del análisis multivariado hasta aquí presentados y de acuerdo con los objetivos que se establecieron al inicio del documento, podemos destacar lo siguiente. En general constatamos con el análisis multivariado lo que se había adelantado en el análisis de sobrevivencia sobre las diferencias entre periodos. De acuerdo con lo esperado, la movilidad de los varones migrantes es menor en las dos últimas épocas respecto del periodo bracero, especialmente en lo referente a migración de retorno. Destaca, sin embargo, que el patrón de movilidad interna parece haberse mantenido constante desde pre-IRCA. En ese sentido, el cambio de política migratoria estaría teniendo un mayor efecto en el retorno, más que en la migración dentro de Estados Unidos.

Por otro lado, destacan las diferencias en el peso de la situación de documentación entre las etapas analizadas. Contar o no con documentos sí tiene un efecto diferenciado sobre la movilidad interna y el retorno, el cual varía según la etapa migratoria. Así, el carecer de documentos inhibe la movilidad interna sólo durante la etapa bracero. Contrariamente a lo esperado, parece ser que la situación de documentación no influye en la movilidad interna en las dos etapas siguientes.

Los resultados en cuanto al retorno según posesión o no de documentos indican variaciones entre las épocas de la migración. En el periodo bracero no hay diferencias significativas en el patrón de retorno según el estatus de documentación al ingresar a Estados Unidos. En el periodo pre-IRCA se observa un efecto positivo sobre las probabilidades de retorno de aquellos migrantes sin documentos compara- 
dos con los que sí los tenían, el cual se mantiene en la misma dirección en la post-IRCA pero con menor intensidad.

Respecto de la movilidad y la ocupación, como cabía esperar, la propensión a la migración interestatal en la agricultura ha resultado ser más del doble ( 2.25 veces mayor) con respecto de aquellos ubicados en otras ocupaciones, y este efecto se mantiene en las diferentes épocas de la migración.

Por su parte, los factores macroeconómicos no tuvieron significatividad estadística para explicar el retorno. Aunque no teníamos hipótesis al respecto, cabe finalmente resaltar el efecto negativo del nivel de empleo en Estados Unidos sobre la movilidad interna, lo que podría implicar que los mexicanos sí se mueven cuando las condiciones laborales son más favorables, probablemente en búsqueda de mejores opciones en estados diferentes al de su llegada.

\section{Conclusiones}

A lo largo de este trabajo se ha puesto de manifiesto la importancia que tienen la ocupación en la agricultura y el estatus de indocumentación cuando se trata de explicar la movilidad laboral de los varones mexicanos en las diferentes épocas de la migración. En el análisis descriptivo se observó como la propensión a migrar, interna o de retorno, es mayor en el primero y segundo año y tiende a descender posteriormente. Destaca también la mayor prevalencia de la migración de retorno frente a la migración interna durante todo el periodo analizado.

Respecto de las variaciones entre épocas, la de los braceros sobresale por la movilidad tanto interestatal como de retorno. La movilidad interestatal es elevada en dicha época en comparación con las épocas pre-IRCA y post-IRCA. Esta mayor movilidad entre estados se explica en parte, pero no totalmente, por la predominancia en esa época de personas ocupadas en la agricultura $(85.5 \%)$. En el análisis multivariado se comprueba que la movilidad interestatal de aquellos hombres ocupados en la agricultura duplica a la de los otros migrantes, efecto que se mantiene constante en las diversas épocas de la migración. En contraste, la relación entre la indocumentación y la movilidad tiene que ser leída en relación con las diferentes etapas, especialmente en el caso de la migración de retorno.

En el planteamiento general de este artículo se asume que los patrones de movilidad interna e internacional de los varones mexicanos 
que llegan a Estados Unidos responden a cambios en las políticas migratorias y al ambiente más o menos favorable frente a la migración indocumentada. Los cambios más recientes en la situación económica por la crisis en Estados Unidos después de 2007, la intensificación del clima antiinmigrante y el aumento en el retorno a México en el último lustro, probablemente conducirían a un cambio en las tendencias al inhibir aún más el retorno de los migrantes indocumentados. El aumento en las migraciones de retorno no voluntarias -vinculadas a la deportación de uno o varios miembros del hogar-suma un elemento más de diferencia con las etapas anteriores. ${ }^{17}$ En la lógica del nuevo patrón de retorno, un estudio de este tipo probablemente tendría que ampliarse a periodos de observación mayores a los cinco años que se consideraron para este trabajo.

Finalmente, por el diseño de la investigación en que nos basamos, este trabajo se centra en la movilidad masculina vinculada a cambios en el empleo. El hecho de centrarnos en la migración laboral de varones excluye otros tipos de movilidad por causas diversas como cambios en los arreglos familiares, eventos en el curso de vida, nostalgia por los lugares de origen, cambios en las necesidades del hogar o percepciones de una mejor calidad de vida en uno u otro destino, entre otras razones. Adicionalmente, es probable que las relaciones entre el estatus de documentación, la etapa de la migración y la ocupación operen de forma distinta si incorporamos a las mujeres a un análisis similar al que se desarrolló en este trabajo. Por ejemplo, estudios anteriores han documentado la mayor preferencia al asentamiento entre las mujeres migrantes latinas radicadas en Estados Unidos (Giorguli e Itzigsohn, 2006). Asimismo, la indocumentación tiene matices distintos entre hombres y mujeres; por ejemplo, las mujeres tienden a utilizar menos el cruce indocumentado (Donato, 2010). Por último, la forma de participación laboral de las mujeres mexicanas en Estados Unidos difiere de la de sus contrapartes varones pues se orientan a sectores distintos (Giorguli y Gaspar, 2008). Para completar la aproximación del análisis conjunto de la migración interna y de retorno que se retoma en este trabajo se requeriría hacer un estudio que incorporara, por un lado, la dinámica de la movilidad de las familias (y con ello, otras razones no necesariamente laborales para

${ }^{17}$ En este trabajo no se ha podido analizar la cuestión de las deportaciones y devoluciones dado que el MMP no incluye ninguna pregunta al respecto. Se considera que el número de deportaciones en la MMP será relativamente escaso, salvo en los años más recientes. En cualquier caso, ésta es una tarea a abordar en futuros trabajos. 
impulsar la migración interna o el retorno) y que estudiara, en específico, las diferencias en los patrones y factores asociados a la movilidad de hombres y mujeres migrantes.

\section{Bibliografía}

Alarcón, Rafael (2011), "U.S. Immigration Policy and the Mobility of Mexicans (1882-2005)", Migraciones Internacionales, vol. 6, núm. 1, pp. 185-218.

Andreas, Peter (2009), Border Games: Policing the U.S.-Mexico Divide, Ithaca, Cornell University Press.

Aparicio Cabrera, Abraham (2011), "Series estadísticas de la economía mexicana en el siglo XX”, Economía Informa, núm. 369, pp. 63-85.

Bureau of Labor Statistics (2013), "Employment Status of the Civilian Noninstitutional Population, 1944 to Date", Household Data. Annual Averages, Washington, United States Department of Labor <http://www.bls.gov/ cps/cpsaat01.pdf> (noviembre, 2013).

Donato, Katharine M. (2010), "U.S. Migration from Latin America: Gendered Patterns and Shifts", The Annals of the American Academy of Political and Social Science, vol. 630, núm. 1, pp. 78-92.

Durand, Jorge (2007), Programas de trabajadores temporales. Evaluación y análisis del caso mexicano, México, Consejo Nacional de Población.

Durand, Jorge y Douglas S. Massey (2003), Clandestinos. Migración México-Estados Unidos en los albores del siglo XXI, México, Universidad Autónoma de Zacatecas / Miguel Ángel Porrúa.

Ellis, Mark y Jamie Goodwin-White (2006), "1.5 Generation Internal Migration in the U.S.: Dispersion from States of Immigration?”, International Migration Review, vol. 40, núm. 4, pp. 899-926.

Fernández Guzmán, Eduardo (2011), "Revisión bibliográfica sobre la migración de retorno”, Norteamérica, vol. 6, núm. 1, pp. 35-68.

Frey, William H. y Kao-Lee Liaw (1999), "Internal Migration of Foreign-Born Latinos and Asians: Are They Assimilating Geographically?”, en Kavita Pandit y Suzanne Davies Withers (coords.), Migration and Restructuring in the United States: A Geographic Perspective, Nueva York, Rowman and Littlefield, pp. 212-230.

Giorguli, Silvia y Selene Gaspar (2008), Inserción ocupacional, ingreso y prestaciones de los mexicanos en Estados Unidos, México, Consejo Nacional de Población.

Giorguli, Silvia, Selene Gaspar y Paula Leite (2007), La migración mexicana y el mercado de trabajo estadounidense. Tendencias, perspectivas y ioportunidades?, México, Consejo Nacional de Población.

Giorguli, Silvia y José Itzigsohn (2006), "Diferencias de género en la experiencia migratoria. Transnacionalismo e incorporación de los migrantes latinos en Estados Unidos", Papeles de Población, vol. 12, núm. 47, pp. 9-37. 
Gurak, Douglas T. y Mary M. Kritz (2000), "The Interstate Migration of U.S. Immigrants: Individual and Contextual Determinants", Social Forces, vol. 78, núm. 3, pp. 1017-1039.

Kritz, Mary M., Douglas T. Gurak y Min-Ah Lee (2012), "Foreign-Born out Migration from New Destinations: Onward or Back to Enclave?", Social Science Research, vol. 42, núm. 2, pp. 527-546.

Lindstrom, David P. (1996), "Economic Opportunity in Mexico and Return Migration from the United States", Demography, vol. 33, núm. 3, pp. 357-374.

Lindstrom, David. P. y Nathanael Lauster (2001), "Local Economic Opportunity and the Competing Risks of Internal and U.S. Migration in Zacatecas", International Migration Review, vol. 35, núm. 4, pp. 1232-1256.

Masferrer, Claudia y Bryan R. Roberts (2012), "Going Back Home? Changing Demography and Geography of Mexican Return Migration”, Population Research and Policy Review, vol. 31, núm. 4, pp. 465-496.

Massey, Douglas S., Jorge Durand y Fernando Riosmena (2006), "Capital social, política social y migración desde comunidades tradicionales y nuevas comunidades de origen en México”, Reis, núm. 116, pp. 97-121.

Massey, Douglas S. y Kristin E. Espinosa (1997), "What's Driving Mexico-U.S. Migration? A Theoretical, Empirical, and Policy Analysis", American Journal of Sociology, vol. 102, núm. 4, pp. 939-999.

Newbold, K. Bruce (1999), "Internal Migration of the Foreign-Born: Population Concentration or Dispersion?", Population and Environment, vol. 20, núm. 3, pp. 259-276.

Nogle, June Marie (1997), "Internal Migration Patterns for U.S. Foreign-Born, 1985-1990”, International Journal of Population Geography, vol. 3, pp. 1-13.

Página web oficial de la MMP (s/f), Proyecto sobre Migración Mexicana, PrincetonGuadalajara, MMP <http://mmp.opr.princeton.edu/home-es.aspx $>$.

Página web de descargas de la MMP (s/f), "Mexican Migration Project", Office of Population Research at Princeton University, Princeton University <http:/ / opr.princeton.edu/archive/mmp $>$.

Tuirán, Rodolfo y José Luis Ávila (2010), "La migración México-Estados Unidos, 1940-2010", en Francisco Alba, Manuel Ángel Castillo y Gustavo Verduzco (coords.), Los grandes problemas de México. Migraciones internacionales, vol. 3, México, El Colegio de México, pp. 93-134.

Zenteno, René y Douglas S. Massey (1999), "Especificidad versus representatividad: enfoques metodológicos para el estudio de la migración internacional", Estudios Demográficos y Urbanos, vol. 14, núm. 1 (40), pp. 75-116. Disponible en: <AIBV7P9YAP8DURN3VFXCFXT5A3D2QJ-3 > y en $<$ revistas. colmex.mx>.

Zolberg, Aristide (2006), A Nation by Design: Immigration Policy in the Fashioning of America, Cambridge, Harvard University Press.

Zúñiga, Víctor y Rubén Hernández León (coords.) (2005), New Destinations: Mexican Immigration in the United States, Nueva York, Russell Sage Foundation. 
Zuñiga, Víctor y Rubén Hernández León (2006), "El nuevo mapa de la migración mexicana a Estados Unidos: el paradigma de la escuela de Chicago y los dilemas contemporáneos en la sociedad estadounidense”, Estudios Sociológicos, vol. 24, núm. 70, pp. 139-165.

\section{Acerca de los autores}

Eduardo Torre Cantalapiedra es maestro en Relaciones Económicas Internacionales y Cooperación por la Universidad de Guadalajara (Jalisco) y la Universidad Rey Juan Carlos de Madrid. Se tituló en la Universidad Complutense de Madrid en las licenciaturas de Derecho; Administración y Dirección de Empresas, y Ciencias Políticas y de la Administración. Es autor del capítulo "Factores determinantes de las políticas inmigratorias estatales y la gestión migratoria multinivel en los Estados Unidos”, en J.C.L. Navarro Chávez y C. Leco Tomás (coords.), Reformas y políticas públicas migratorias, Morelia, Instituto de Investigaciones Económicas y Empresariales de la Universidad Michoacana de San Nicolás de Hidalgo, 2014. En los años 2012 y 2013 fue distinguido con el Premio a la Excelencia Colmex que otorga la Fundación BBVA Bancomer. En 2014 se hizo acreedor de una Beca Santander de Movilidad Nacional para la realización de una estancia de investigación en El Colegio de la Frontera Norte y fue elegido becario del Ryoichi Sasakawa Young Leaders Fellowship Fund de la Fundación Tokio. Actualmente cursa el doctorado en Estudios de Población en El Colegio de México (promoción 2012-2016).

Silvia E. Giorguli es profesora investigadora en el Centro de Estudios Demográficos, Urbanos y Ambientales de El Colegio de México; fue directora de dicho centro de 2009 a marzo de 2015. Socióloga y demógrafa, obtuvo el grado de maestría en Demografía en El Colegio de México y el doctorado en Sociología en la Universidad de Brown. Entre 2007 y 2008 fue investigadora visitante en el Center for the Advanced Study of Behavioral Sciences de la Universidad de Stanford. Pertenece a diversas asociaciones profesionales y es miembro del Sistema Nacional de Investigadores (SNI-II). Fue vicepresidenta (20062008) y presidenta (2011-2013) de la Sociedad Mexicana de Demografía. Es fundadora y fue directora editorial (2011-2014) de la revista Coyuntura Demográfica. Revista sobre los Procesos Demográficos en México Hoy, publicación semestral de la Sociedad Mexicana de Demografía. Su 
investigación se ha concentrado en las implicaciones del cambio demográfico sobre el desarrollo, la migración internacional entre México y Estados Unidos y las transiciones a la vida adulta en América Latina. Entre sus publicaciones recientes destaca la coordinación del libro Gobierno, territorio y población: las políticas públicas en la mira (2014), editado por El Colegio de México; y el capítulo "International Migration, Gender and Family: A Miroir from Latin America" (en prensa), en el Handbook of International Migration, editado por Springer y coordinado por Michael White. 
